\title{
Precipitation Constrains Amphibian Chytrid Fungus Infection Rates in a Terrestrial Frog Assemblage in Jamaica, West Indies
}

\author{
Iris Holmes ${ }^{1,3}$, Kurt McLaren ${ }^{2}$, and Byron Wilson ${ }^{2}$ \\ ${ }^{1}$ Museum of Zoology, University of Michigan, 1109 Geddes Ave, Ann Arbor, MI 48109, U.S.A. \\ ${ }^{2}$ University of the West Indies, Mona Campus, Kingston 7, Jamaica, West Indies
}

\begin{abstract}
We model Batrachochytrium dendrobatidis (Bd) infection rates in Jamaican frogs — one of the most threatened amphibian fauna in the world. The majority of species we surveyed were terrestrial direct-developing frogs or frogs that breed in tank bromeliads, rather than those that use permanent water bodies to breed. Thus, we were able to investigate the climatic correlates of $B d$ infection in a frog assemblage that does not rely on permanent water bodies. We sampled frogs for $B d$ across all of the major habitat types on the island, used machine learning algorithms to identify climatic variables that are correlated with infection rates, and extrapolated infection rates across the island. We compared the effectiveness of the machine learning algorithms for species distribution modeling in the context of our study, and found that infection rate rose quickly with precipitation in the driest month. Infection rates also increased with mean temperature in the warmest quarter until $22{ }^{\circ} \mathrm{C}$, and remained relatively level thereafter. Both of these results are in accordance with previous studies of the physiology of $B d$. Based on our environmental results, we suggest that frogs occupying high-precipitation habitats with cool rainy-season temperatures, though zcurrently experiencing low frequencies of infection, may experience an increase in infection rates as global warming increases temperatures in their habitat.
\end{abstract}

Key words: Batrachochytrium dendrobatidis; Eleutherodactylus; infectious disease; machine learning; niche modeling; Osteopilus; West Indies.

THE FUNGAL PATHOGEN BATRACHOCHYTRIUM DENDROBATIDIS (BD) HAS CAUSED EXTINCTIONS and catastrophic population declines in over 350 amphibian species (Lips et al. 2006, Blaustein et al. 2012), with particularly high impacts in tropical regions. The pathogen has been little studied on Jamaica. Identifying the threats to Jamaican frogs is a conservation priority because they are little studied, and face the same threats, such as habitat loss and introduced predators, which are causing amphibian declines elsewhere in the Caribbean (Hedges 2011). The current Caribbean amphibian biodiversity crisis is compounded by widespread $B d$ infection in the region (Burrowes et al. 2004, Diaz et al. 2007, Alemu et al. 2008, Longo \& Burrowes 2010, Patel et al. 2012, Longo et al. 2013). The fungus has caused documented declines in Puerto Rican and Central American amphibians, many of which are ecologically and phylogenetically similar to Jamaican frogs (Lips et al. 2006, Puschendorf et al. 2009, Whitfield et al. 2012). Several of our focal frog species have disappeared from undisturbed sites at which they were formerly abundant, raising concerns about their population trends (Holmes et al. 2012). Here, we ask which climatic variables are correlated with increased proportions of infected frogs in Jamaica, and form hypotheses as to why significant correlations occur based on $B d$ physiology.

Jamaica has 21 endemic species of frogs in the genera Eleutherodactylus (17 species) and Osteopilus (4 species) (Hedges 1989, Moen \& Weins 2009). The Jamaican Eleutherodactylus are direct

Received 20 August 2013; revision accepted 9 December 2013.

${ }^{3}$ Corresponding author; e-mail: iah6@cornell.edu

(c) 2014 The Association for Tropical Biology and Conservation developers and lay their egg under rocks, logs, or in caves (Diesel et al. 1995, Gomez-Mestre et al. 2012). The Osteopilus species deposit their eggs in tank bromeliads (Lanoo et al. 1987). Thus, Jamaica's endemic frogs are independent of large, permanent water bodies, and so provide an opportunity to examine the epidemiology of $B d$ in a terrestrial frog fauna. The $B d$ organism is primarily aquatic (Berger et al. 2005). Batrachochytrium dendrobatidis begins its life cycle as a flagellated, free-living zoospore, which is the dispersal phase for the fungus. Zoospores of $B d$ can swim short distances, and exhibit chemotaxis and phototaxis (Moss et al. 2008). Zoospores can remain viable in damp ground for up to 3 mo (Longcore et al. 1999), but desiccate within $3 \mathrm{~h}$ when no moist microclimate is available (Piotrowski et al. 2004). High humidity increases the likelihood that an amphibian host will be reinfected when current encysted sporangia release zoospores (Murray et al. 2013).

Batrachochytrium dendrobatidis is also temperature sensitive. Temperatures below $10{ }^{\circ} \mathrm{C}$ and above $25{ }^{\circ} \mathrm{C}$ reduce the fungus's growth rate in vitro (Piotrowski et al. 2004), while long-term exposure to temperatures between 26 and $33{ }^{\circ} \mathrm{C}$ allows frogs to clear $\mathrm{Bd}$ infection in the laboratory (Chatfield \& RichardsZawacki 2011, Geiger et al. 2011). Even short-term exposure (1 h) to temperatures above $30{ }^{\circ} \mathrm{C}$ can drastically reduce the growth rate of $B d$ in vitro (Daskin et al. 2011). In the field, high temperatures are correlated with low to absent $B d$ loads in frogs that carried the fungus at lower temperatures (Forrest \& Schlaepfer 2011, Rowley \& Alford 2013). Growth rates of Bd within an individual frog show a strong correlation with disease prevalence in a population, both in the field and in simulation studies (Murray 
et al. 2013). Therefore, interpretation of landscape-scale niche modeling results can be usefully informed by in vitro or individual-focused laboratory studies of $B d$ physiology.

Previous model-based studies of $B d$ in tropical and subtropical regions have identified both high temperatures and low precipitation as correlates with reduced infection rate (Drew et al. 2006, Forrest \& Schlaepfer 2011, Ghirardi et al. 2011, Murray et al. 2011, Whitfield et al. 2012). However, Bd does occur where large-scale models predict its absence (Puschendorf et al. 2011, Flechas et al. 2012, Whitfield et al. 2012, Ocock et al. 2013). Further, there are multiple strains of $B d$ worldwide, and their diversity has yet to fully cataloged (Martel et al. 2013, Rosenblum et al. 2013). In vitro experiments with the physiological tolerance of one $B d$ strain do not necessarily reflect the climatic tolerance of the local strain, or the interaction between that strain and the immune systems of the focal frog species (Van Rooij et al. 2012, Stevenson et al. 2013). Hence, local sampling and modeling are vital for conservation planning.

Life-history strategy of amphibian hosts is relevant to $B d$ epidemiology. In studies comparing sympatric frogs, species associated with permanent water bodies have higher $B d$ infection rates than those that breed by direct development or use ephemeral water bodies (Rowley \& Alford 2007, Bancroft et al. 2011, Hauselberger \& Alford 2012, Olson et al. 2013). Time spent in water is positively correlated with individual $B d$ infection rates within species (Hossack et al. 2013). As host life-history strategy influences $B d$ dynamics on a species-specific level, we hypothesize that a largely terrestrial frog community will impose an unusual set of epidemiological constraints on the fungus. Jamaica has such a frog fauna (Lanoo et al. 1987, Diesel et al. 1995, Gomez-Mestre et al. 2012).

Our study will facilitate conservation planning for Jamaican frogs as well as other primarily terrestrial amphibian assemblages that may be at risk from $B d$. We also compare the results of different niche modeling approaches. Such comparisons have been performed on many taxa (Sehgal et al. 2011, Bisrat et al. 2012, Oppel et al. 2012), but have been rare for Bd. Using multiple niche modeling techniques allows us to distinguish between climatic variables that have a consistent correlation with $B d$ infection rates across approaches, and those that appear significant only as a result of the assumptions of one approach. If a variable is consistently uncovered by multiple methods, we increase our confidence that it is biologically relevant. Our work contributes new tools for conservation planning both in Jamaica and other tropical locations where terrestrial frogs are common.

\section{METHODS}

SAMPLING.-We sampled a variety of habitats across the island (Table S1). All sampling sites were separated by more than $5 \mathrm{~km}$. To check for autocorrelation in infection rate between our sampling sites, we used the Moran's I (Moran 1950) statistic implemented in R v. 2.12 .1 (R Development Core Team 2010) using the package 'ape' (Paradis et al. 2004). For each site, we scored the season during which it was sampled as: major wet from 1
September to 1 December, major dry from 2 December to 1 April, minor wet from 2 April to 1 June, and minor dry from 2 June to 1 September. Although we visited most sites once, we sampled each of the major habitat types (wet, moist, and dry tropical rain forest, cloud forest, and Amazonian swamp forest) in several seasons. We made a linear model in $\mathrm{R}$ with sampling season as the independent variable and infection rate as the dependent variable to capture broad-scale seasonal changes in $B d$ infection rate. We opportunistically sampled non-native frogs and crustaceans. For further details, please see the online Supporting Information.

LABORATORY PROTOCOLS.-We extracted $B d$ genomic DNA from our swabs using PrepMan Ultra, and used the DNA for quantitative polymerase chain reaction (qPCR) tests to evaluate infection status (Hyatt et al. 2010). Although our laboratory protocol gave us load data in zoospore equivalents for each infected frog, we considered only the per-individual presence or absence of infection for our statistics. For further detail on our rationale for this approach, please see the online Supporting Information.

INFECTION RATE CORRELATES.-We used macroclimatic data from WorldClim (Hijmans et al. 2005) for niche modeling $B d$ in Jamaica. We chose to focus on climatic variables rather than proxies (i.e., elevation), so that we could directly model the climatic niche of the fungus in Jamaica. The variables we used, and the abbreviations by which we have referred to them in this paper, are in Table S2. The layers reflected average values for at least $10 \mathrm{yr}$ between 1960 and 1990. In addition, we used latitude and longitude to identify patterns of $B d$ distribution that are not explained by climatic variation. Such patterns could have arisen if $B d$ was introduced recently and was still radiating through the island from its introduction point, or if some geographical or climatic feature presented a barrier to the fungus, preventing it from occupying otherwise suitable habitats. We also used a categorical representation of the season during which each site was sampled.

VARIABLE SELECTION: MAXIMUM RELEVANCE, MINIMUM REDUNDANCY.-To identify the set of WorldClim variables that best explained infection rates in our sampled locations, and narrow the number of variables passed to the modeling algorithms, we implemented an information theoretic variable selection algorithm using the 'infotheo' package (Meyer 2008, 2009) in R. Our selection method identified a set of variables that, as a group, explain as much variation in the data as the entire set of variables. Although the minimum redundancy criterion reduced colinearity among explanatory variables, it did not completely account for it. We handled colinearity issues separately in our subsequent modeling approaches.

Following the default setting, we binned the data into five bins, the square root of the number of localities rounded to the nearest integer. We used mutual information to quantify the reduction in uncertainty of the predicted value of a variable given known values of another variable at the sampling sites. Mutual 
information was zero when the two variables are independent of each other, and increased with the ability of the value of one variable at a site to predict the value of the other. We measured mutual information in nats, a unit based on the natural logarithm e. One nat is approximately equal to 1.44 bits, a measure based on $\log$ base 2 .

We used a filter-based forward selection approach whose criterion for selection was minimal redundancy and maximal relevance (MRMR) (Meyer 2008). We first selected the variable that had the highest mutual information with the infection rates. We added subsequent variables by selecting the remaining variable that had the optimal trade-off between having high individual mutual information with the infection rates (maximizing relevance) and low mutual information with the already-selected variables (minimizing redundancy). We continued adding variables until our selected set reached the mutual information of the entire set of WorldClim variables, indicating that all further variables were redundant to those already selected.

VARIABLE SELECTION: RANDOM FOREST.-We used a Random Forest algorithm (Breiman 2001) implemented in the R package 'randomForest' (Liaw \& Wiener 2002) to build a forest of regression trees. Individual regression trees were weak predictors that partition a given data set into maximally homogeneous groups based on provided explanatory variables. For each split, the tree searched through all possible breaking points in the explanatory variables, and selected the variable and split point that grouped the data into maximally homogenous clusters. The Random Forest algorithm introduced stochasticity to the process of building regression trees, thereby eliminating over-fitting and improving the predictive ability of the final forest over any single tree. For each tree, the algorithm randomly selected two-thirds of our sampling locations for use as training data. These localities were the 'in-the-bag' data for that tree. The remaining data were 'out-ofbag' data, and were used to assess the predictive ability of the tree. The Random Forest algorithm introduced additional stochasticity to its individual trees by randomly selecting a subset of the explanatory variables for the tree to examine at each node. The algorithm arrived at its final prediction by taking the majority votes of the trees (as determined by the tree's performance on the out-of-bag data) for the correct splitting of the training data at each node (Breiman 2001).

By iteratively removing and permuting the values of the explanatory variables and comparing the resulting increase in mean squared error (MSE) in the out-of-bag predictions to those of the original tree, Random Forest assessed variable importance. Randomizing important variables resulted in greater increase in MSE than randomizing unimportant variables. We ran the variable selection ten times to account for stochasticity in model development and averaged the MSE's to identify important variables.

We built Random Forests with the most important variable identified by the above process. We also built forests with the two most important variables, and the eight variables that increased MSE when noised, and with the MRMR identified vari- ables. We selected the model with the best predictive ability by jack-knifing over collection locations. We extrapolated the percentage of individuals infected at each sampled site based on a model trained on the data of all other sampling locations. We assessed the success of each model in extrapolating by finding the MSE of these predictions using the 'hydroGOF' (ZambranoBigiarini 2011) package in R. We found the correlation coefficient $\mathrm{R}^{2}$ of the predictions using the function ' $\mathrm{Im}$ ' and the Pearson correlation using the function 'cor.' We use the variables selected by the Random Forest with the highest $R^{2}$ for extrapolation of infection rates to all of Jamaica.

MODELING: RANDOM FOREST.-We used the variables identified by the MRMR variable selection and the best fitting model from the Random Forest variable selection to predict $B d$ infection intensities across the island. We plotted the results in $\mathrm{R}$ using the package 'sp' (Pebesma \& Bivand 2005, Bivand et al. 2008).

MoDeling: Gam.-We used the package 'gam' in $\mathrm{R}$ to calculate a Generalized Additive Model for our data (Hastie \& Tibshirani 1990). We used Aikaike information criterion (AIC) scores to identify the best fit model. We tested all individual predictors, and selected the predictor with the highest AIC. We then tested all combinations of the selected variable and the remaining variables. Adding any third variable decreased AIC, so we selected the best two-variable model for prediction of infection rate across the island. We validated the model using the MSE of predictions from jack-knifing over sites. We determined the $R^{2}$ and Pearson correlation of the predictions in $\mathrm{R}$. We predicted infection rates across the entire island and plotted them using the 'sp' package (Pebesma \& Bivand 2005, Bivand et al. 2008).

Modeling: MaXent.-The Maximum Entropy algorithm used presence-only data to predict the likelihood that $B d$ will occur in a given area (Phillips et al. 2006, Phillips \& Dudik 2008, Puschendorf et al. 2009). The algorithm used explanatory habitat variables to build potential distributions of $B d$ across Jamaica, such that the expected values of those distributions were identical to the empirical average of the variables at the locations where we detected $B d$. The algorithm selected the distribution that displays maximum entropy, that is, the distribution closest to uniform. By transforming our linear features (WorldClim variables) into quadratic features, we constrained the variance of the explanatory variables in the selected distribution to be identical to the variance of the variables between the collection locations.

We first assessed the importance of each environmental variable in the MRMR set by building a model using the entire set of positive collection locations. We jack-knifed over the environmental variables to determine which ones held the most explanatory power for our data in presence-only form. We then predicted $B d$ infection rates over the entire island using the variable selected by jack-knifing. We used the area under the curve (AUC) values calculated in MaxEnt to identify the model with the highest explanatory power. AUC measured the probability that a site that 
is positive for $B d$ is classified correctly by the algorithm. We predicted the $B d$ distribution across Jamaica using $\mathrm{L}+\mathrm{Q}$ features from the MRMR selected variables and the model with the highest AUC value.

EFFECT SIZE OF BIOLOGICALLY RELEVANT VARIABLES.-To account for sampling effects introduced by unequal sample sizes at our various sites, we generated 500 synthetic data sets by resampling ten infection records from each location with replacement. We plotted the resulting data against the precipitation in the driest month (PDM) and mean temperature in the wettest quarter (MTWQ) (the climatic variables most consistently identified as biologically relevant) for each site, and fit a smoothing spline with seven degrees of freedom to assess the robustness of the effect of the variable to stochasticity in the sampling process (Cleveland et al. 1992). We also fit a loess curve based on a first-degree polynomial with PDM or MTWQ as explanatory variables and infection rate as the response variable (Hastie \& Tibshirani 1990, Cleveland et al. 1992, Green \& Silverman 1994). We found the 95 percent confidence interval for the curves, and located the peak of each using the 'optimize' function in R.

\section{RESULTS}

SAMPLING SITES AND BD LOADS.-The Moran's I test for autocorrelation in infection rates between sampling sites was not significant $(P=0.4830)$. The linear model of sampling season vs. infection rate did not show a significant effect of sampling season on $B d$ load $\left(P=0.2168, R^{2}=0.8344\right)$. One of two Sesarmid land crabs and one of 12 crayfish, all sampled along the Stony River, tested positive for $B d$ (Table S3). With the caveats presented in the methods section regarding swab storage and copy number variation, across our sites, the average $B d$ load per infected frog was 110.1 ( \pm 379.3 ) zoospore equivalents. The median load was 7.36 zoospore equivalents. The highest load was 2635.0 and the lowest was 0.07 equivalents.

VARIABLE SELECTION: MRMR.-The mutual information between all twenty WorldClim variables, latitude, longitude, and sampling season and infection rates was 1.12 nats. The MRMR criterion selected eight variables: AP, latitude, PDM, MTWQ, MDR, TS, PS, and ISO. After the addition of ISO, the set of seven reached a mutual information value of 1.12 nats, the same as the total data set. The addition of further variables did not change the total mutual information value, and we considered all other variables redundant.

VARIABLE SELECTION: RANDOM FOREST.-Random Forest variable selection identified PDM and precipitation in the driest quarter (PDQ) as the two most important variables (Fig. S1). Neither latitude nor longitude was identified as an important variable. Jackknifing results showed the lowest MSE and highest correlation for the PDM-only model, while the PDM/PDQ, MRMR, and the model with all variables identified by the Random Forest variable selection had lower values (Table 1).
TABLE 1. Models tested by jack-knifing over collection locations, with the mean squared error, correlation coefficient, and Pearson correlation for each model.

\begin{tabular}{lccc}
\hline Model & MSE & $\mathrm{R}^{2}$ & $\begin{array}{c}\text { Pearson } \\
\text { correlation }\end{array}$ \\
\hline RF-MRMR & 0.0122 & -0.035 & 0.151 \\
RF-PDM & 0.0089 & 0.183 & 0.478 \\
RF-PDM+PDQ & 0.0093 & 0.168 & 0.463 \\
RF-all variables & 0.0105 & 0.060 & 0.335 \\
GAM & 0.0114 & 0.079 & 0.360 \\
\hline
\end{tabular}

MODELING: RANDOM FOREST.-Partial dependency of infection rates on variables showed that infection rate increased gradually with AP, from an average of 13 percent of frogs infected in areas with $1000 \mathrm{~mm}$ of rainfall per year to a 17 percent infection rate where annual precipitation is $2500 \mathrm{~mm}$. Infection rate increased from 12 percent when PDM is $60 \mathrm{~mm}$ to 18 percent when it is above $80 \mathrm{~mm}$. The response of infection rate to MTWQ was smaller than to the precipitation variables. When MTWQ is $16{ }^{\circ} \mathrm{C}$, the average for the marginal distribution of infection rate is 15.5 percent. As MTWQ increases to $24{ }^{\circ} \mathrm{C}$, this value steadily rises to 16 percent, and then drops to below 15 percent when MTWQ increases over the $24^{\circ} \mathrm{C}$ threshold.

Predictions of infection rates by the MRMR model showed that infection should be highest in the eastern mountains, intermediate in the central lowland rain forest, and lowest along the southern and western coasts (Fig. 1A). Predictions by the PDM model indicated that infection rates should be high in areas of the eastern mountains and the central lowland tropical rain forest. The PDM model predicted higher infection rates over much of the country (Fig. 1B).

Modeling: GAM.-In the model with the lowest AIC, infection rates were explained by PDM and MTWQ, smoothed with one degree of freedom. AIC was -30.89463 , and the MSE of the jack-knifed sites was 0.00912, close to the PDM-only Random Forest model. We used the PDM+MTWQ model to predict infection rates for the entire island (Fig. 2). Predicted rates were much higher than those of the Random Forest model, reaching predictions of 70 percent infected, a value much higher than any of our samples. As we were unable to sample in the area projected to have a 70 percent of frogs infected, we cannot directly test the accuracy of this prediction.

Modeling: MAXENT.-The variable identified as most important by jack-knifing was PDM. The AUC for this variable alone was the highest of any individual variable. Several other precipitation variables showed similar but smaller AUC's, but all of these variables have high levels of dependence on PDM, and the MRMR results showed that all but AP are redundant when PDM was included in the data set.

The average AUC value for the model PDM model was 0.775. The average AUC for the MRMR variable set was 0.697. 

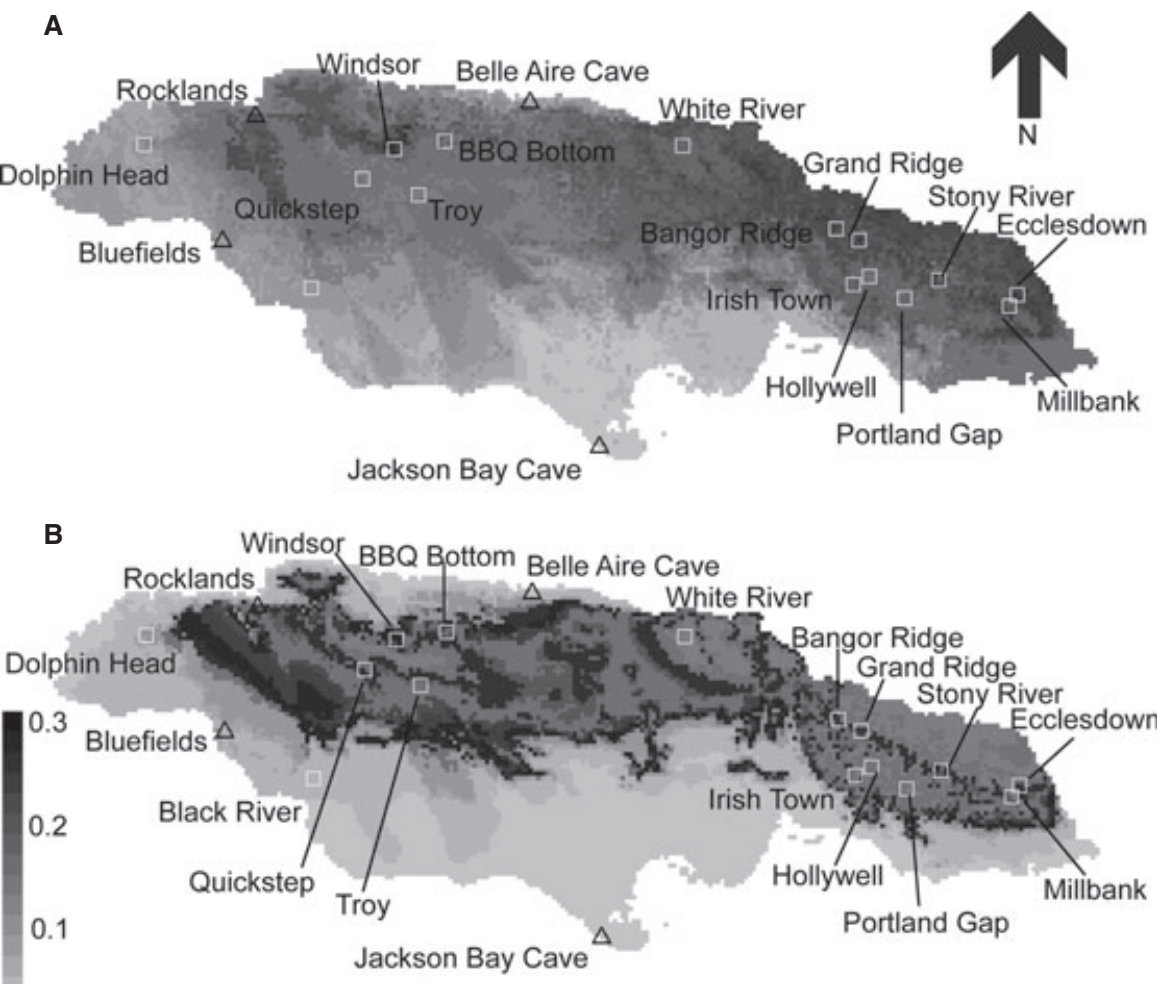

FIGURE 1. Infection rates across Jamaica predicted by the PDM model (A). Infection rates as predicted by the MRMR-selected variables in Random Forest (B). Black indicates the highest probability of infection, white the lowest. Sampling sites at which frogs tested positive for $B d$ are indicated with a white square, while those with no $B d$ are indicated by a black triangle.

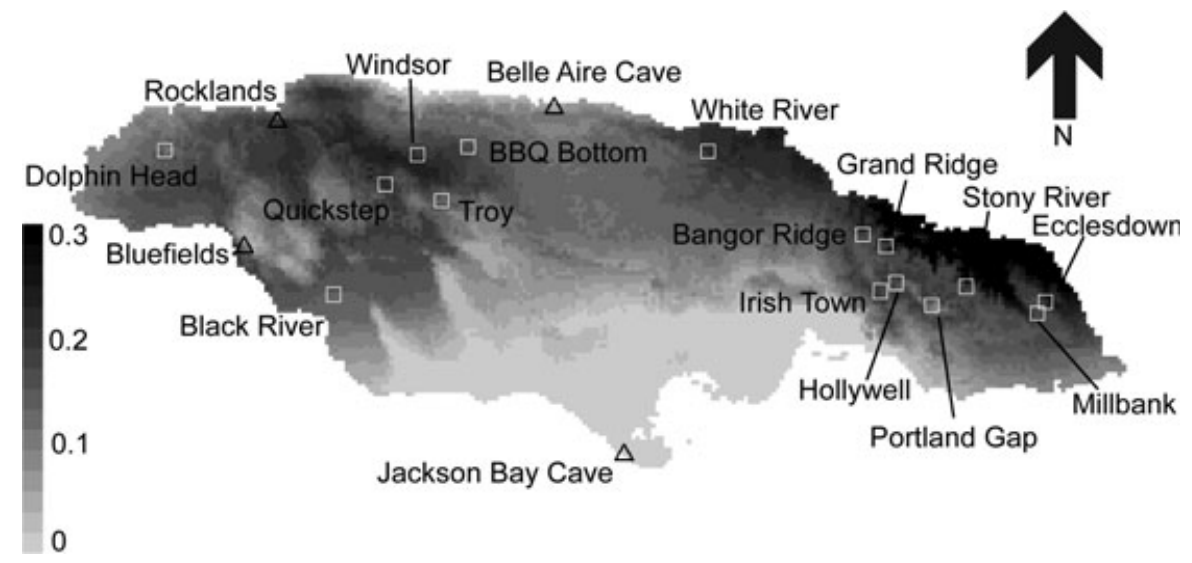

FIGURE 2. Infection rates as predicted by the PDM+MTWQ GAM model. Black indicates the highest probability of infection, white the lowest. Sampling sites at which frogs tested positive for $B d$ are indicated with a white square, while those with no $B d$ are indicated by a black triangle.

We used the PDM model and the MRMR model to predict infection rates across the entire island. The PDM model showed more even rates, with an area of high infection likelihood on the northeast coast (Fig. 3A). The MRMR model added an area of high likelihood near the peak of Blue Mountain, and predicted lower infection rates along the southern and western coasts (Fig. 3B).
EFFECT SIZE OF BIOLOGICALLY RELEVANT VARIABLES.-Resampling within locations showed an increase in the lower bound of the infection rate splines at approximately $55 \mathrm{~mm}$ of PDM and an increasing trend in infection rate with mean temperature of the wettest quarter (Fig. 4). Infection rate increased slightly with MTWQ. Results were similar for the loess curves, with the 95 


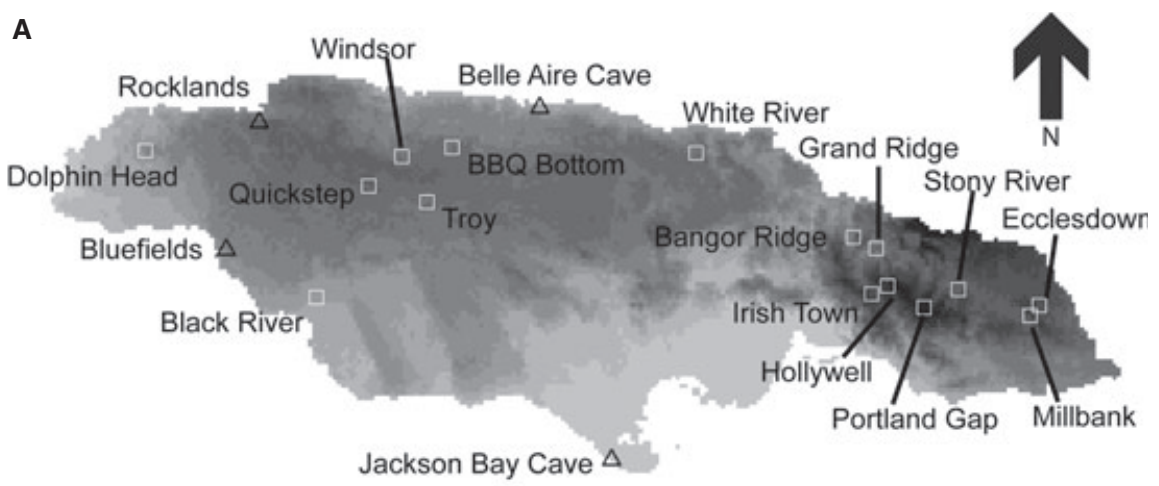

B

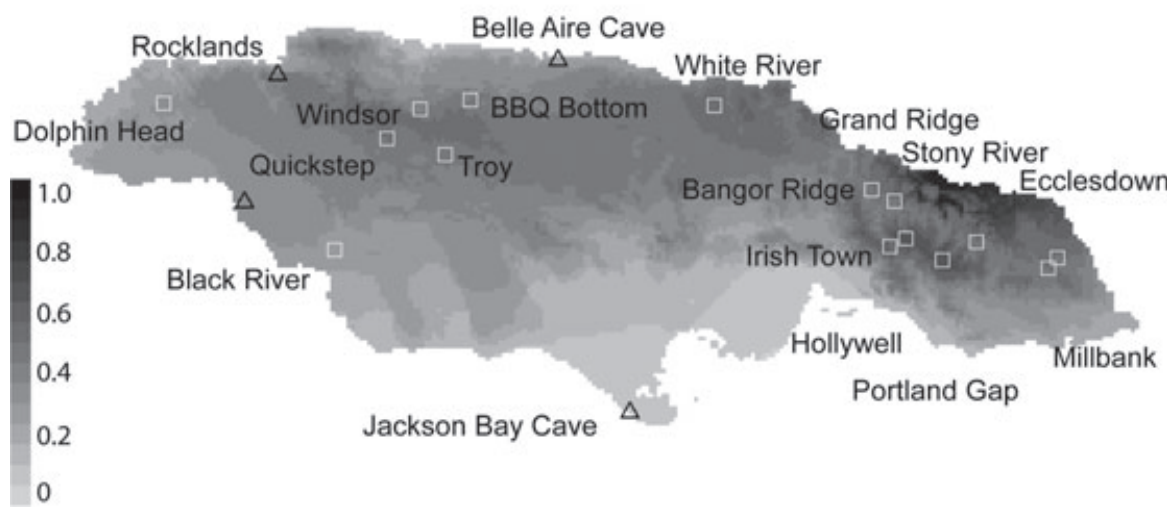

FIGURE 3. Infection probability as predicted by MaxEnt for the (A) PDM model and (B) the MRMR model with linear and quadratic features. Black indicates the highest probability of infection, white the lowest. Sampling sites at which frogs tested positive for $B d$ are indicated with a white square, while those with no $B d$ are indicated by a black triangle.

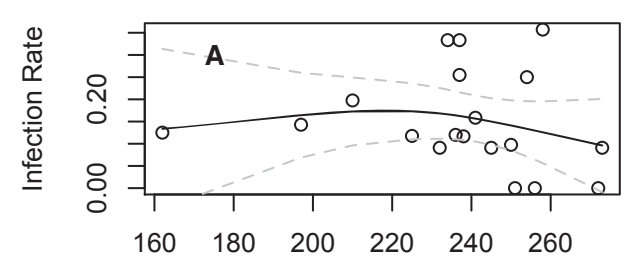

Mean Temp Wettest Quarter(degrees Cx10)

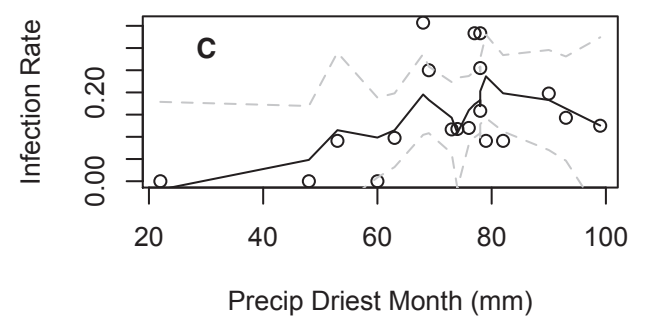

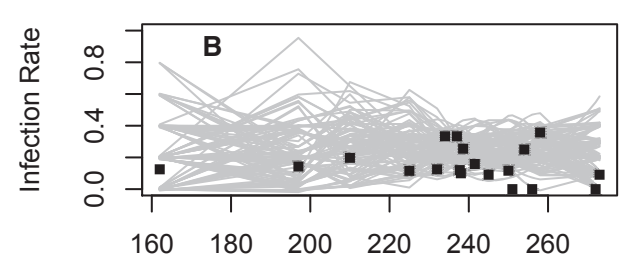

Mean Temp Wettest Quarter(degrees Cx10)

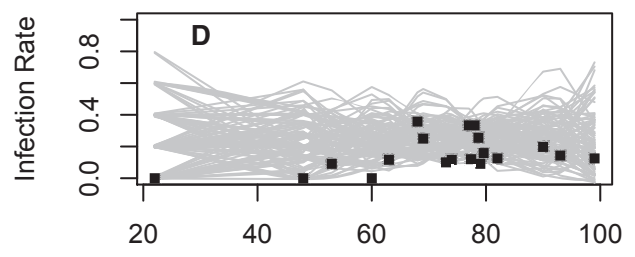

Precip Driest Month (mm)

FIGURE 4. (A) Loess model of Bd infection rate vs. mean temperature of the wettest quarter. Dashed lines are $95 \%$ CI. Open boxes are data points, filled circle is the apex of the predicted curve. (B) Smoothed splines from 500 resamplings of the infection data at each location vs. mean temperature in the wettest quarter. (C) Loess model of Bd infection rate vs. precipitation in the driest month (PDM). (D) Smoothed splines of 500 resamplings of data vs. PDM. 
percent confidence interval for the lower bound of the PDM curve becoming significant at $58 \mathrm{~mm}$ and the high point of the peak at $68 \mathrm{~mm}$. The MTWQ loess curve peaked at $21.7^{\circ} \mathrm{C}$. Both approaches showed that our while data are scattered and variable effect sizes are small, the $60 \mathrm{~mm}$ PDM threshold is consistently recovered. In the randomizations, the smallest infection rates shown by smoothing splines rose above zero percent infection, and the 95 percent CI for the loess model stops including zero percent infection. Both approaches show a gradual increase in infection rate relative to MTWQ (Fig. 4).

\section{DISCUSSION}

BIOLOGICALly RELEVANT VARIABLES.-Our variable selection and species distribution modeling methods all identified PDM as critical for determining the proportion of frogs infected with $B d$ at our sampled sites (for MRMR variable selection, Random Forest, GAM) or probability of presence (for MaxEnt). Batrachocbytrium dendrobatidis infection rates were lowest in areas with less than $60 \mathrm{~mm}$ rainfall in the driest month, and increased with precipitation above that threshold (Fig. 4).

Previous modeling studies on $B d$ have identified precipitation variables as important to $B d$ distribution. A worldwide model used temperature variables to split temperate and tropical areas, and used PDM to model infection probability within each of these zones (Ron 2005). MaxEnt modeling of $B d$ in Costa Rica found that PDQ and annual mean temperature were the most important correlates to $B d$ presence (Puschendorf et al. 2009). Previous laboratory studies demonstrate that $B d$ is strongly constrained by moisture levels. While it can remain viable in damp ground for up to 3 mo (Longcore et al.1999), zoospores desiccate within $3 \mathrm{~h}$ in dry areas (Poirtrowski et al. 2004).

Batrachochytrium dendrobatidis physiology may also explain why MTWQ is the most important temperature variable identified by the MRMR and GAM algorithms. If dry periods constrain the times at which $B d$ can persist in the environment, the wettest month should be a window of opportunity for $B d$ to infect new hosts. Therefore, the fungus's rate of reproduction in this month should be crucial to its ability to spread and increase infection rates. At $23{ }^{\circ} \mathrm{C}, \mathrm{Bd}$ zoospores can clonally reproduce within $24 \mathrm{~h}$ of infecting a host (Voyles et al. 2012). At lower temperatures, it takes longer to encyst and reproduce (Voyles et al. 2012). Slight increases in the rate of $B d$ life cycle can result in large differences in disease dynamics, as infection rate can increase exponentially both within an individual and within a population (Murray et al. 2009, 2013, Briggs et al. 2010). The loess model shows that $B d$ rates raise with temperature until mean temperature of the wettest month reaches $22{ }^{\circ} \mathrm{C}$, and are relatively stable thereafter, a result in accordance with previous work on the thermal optimum of the fungus (Poirtrowski et al. 2004).

Method COMPARISON.-The MRMR model did not find that season of sampling was an important predictive variable for $B d$ infection rate, and there was no significant correlation between infection rate and season in a linear model. Each of our major habitats was sampled in two or more seasons, so we do not explicitly model season of sampling in our predictive techniques. Predictions at a given location are best understood as the infection rate of the probability of presence of $B d$ averaged throughout the year.

All of our modeling approaches are necessarily based on sets of assumptions. MaxEnt assumes that the most accurate distribution will be the most uniform in terms of the explanatory variables (Phillips et al. 2006, Phillips \& Dudik 2008). Random Forest assumes that it is useful to break the collection locations into maximally homogeneous groups, each identified by a set of values of the explanatory variables (Breiman 2001). GAM's assume that the variation in the infection rate can be explained by a linear smooth of a set of explanatory variables (Hastie \& Tibshirani 1990). These assumptions are all intuitively reasonable, but not directly testable with our data set. They are also not mutually exclusive.

Because it is extremely difficult, a priori, to identify the set of assumptions that best fit the distribution of $B d$ in our study area, we used multiple modeling approaches and compared their success in extrapolating to areas not included in the training data (Bisrat et al. 2012, Oppel et al. 2012). To do so, we jack-knifed over our collection locations and found the MSE, $R^{2}$, and Pearson correlation coefficient of the predictions. We found that the Random Forest PDM-only model was the best predictor according to all of these tests, followed by the PDM and PDQ model and the GAM (Table 1). Our extreme values for infection rate $(0$ percent and 30 percent) are derived from smaller sample sizes than those in the mid-range of infection rate. To determine whether these samples drove the patterns we found, we resampled the infection status of the frogs collected at each location with replacement, thereby forming 500 synthetic data sets with equal sample sizes at each location, whose variation reflected the uncertainty introduced by sampling. We plotted the synthetic data against PDM and MTWQ at each sampling site and fit smoothing splines. These splines show that we can expect considerable variation at the top range of our estimates of infection rate, but the lower bounds are relatively constant across randomizations. Thus, the conservative approach for conservation planning is to accept observed infection rates as the probable lower bound for actual infection rate at a given location.

FutURE DIRECTIONS.-Vertical transmission is another factor to consider in disease dynamics. Many frog species in Jamaica display parental care. At least two species of Eleutherodactylus show parental transport of newly hatched froglets (Diesel et al. 1995, I. Holmes pers. obs.). Osteopilus brunneus lay sterile eggs as food for their oophagous tadpoles, which are reared in tank bromeliads (Lanoo et al. 1987). The high level of contact between froglets and parents may present a greater opportunity for infection in the next generation than is found in other frog assemblages, or an opportunity to transmit skin flora that protect young frogs from $B d$ (Walke et al. 2011).

Jamaican frogs should also be tested for emerging infectious diseases other than $B d$. Various Ranaviruses infect frogs world- 
wide and may lead to decline, either on their own or in concert with Bd (Gray et al. 2009). Recent work has identified a new species in the genus Batrachochytrium, B. salamandrivorans, which has similarities to $B d$ but is not amplified by the $B d$ primer we used in this paper (Martel et al. 2013). These and other infectious diseases should be investigated and considered in future conservation planning,

CONSERVATION IMPLICATIONS.-Batrachochytrium dendrobatidis dynamics are highly variable depending on the life-history strategies of the infected frogs, the strain of $B d$ present, and the macroclimate in which infection occurs. Without heavy use of a permanent water body by widespread infected species, variation in precipitation becomes more important to infection rates than temperature, even when annual precipitation is relatively high by global standards. Our results indicate that the wet eastern coast of Jamaica is the area with highest risk for $B d$-related decline. Areas with less than $60 \mathrm{~mm}$ of rain in the driest month and average temperatures above $22{ }^{\circ} \mathrm{C}$ in the wettest quarter show low $B d$ infection rates. Infection rates are also lower where the MTWQ is below $18{ }^{\circ} \mathrm{C}$.

As temperatures increase in high-precipitation habitat due to global warming, $B d$ growth rates are likely to increase, which will increase the frogs' risk for chytridiomycosis-related declines. Continued monitoring should be focused on areas of high precipitation and those in which the MTWQ is greater than $20^{\circ} \mathrm{C}$ but less than $24^{\circ} \mathrm{C}$.

Our results are generalizable to other tropical amphibian populations that are composed of mainly terrestrial species, at local and regional scales. The ecology and epidemiology findings of $B d$ show unique dynamics in terrestrial species. As such, vulnerable terrestrial species should be monitored.

\section{ACKNOWLEDGMENTS}

We thank D. Luke, C. Sharma, S. Monroe, K. Prospere, S. B. Hedges, K. Lewis, J. Pauel, S. Stewart, M. Grundler, T. Shields, P. Doughty, and L. Johnson for valuable assistance in the field, and P. Tennant, R. Bair, K. Zamudio, A. Longo Barrios, and D. Rodriguez for help with laboratory work. We benefited greatly from the assistance of the Jamaica Caves Organization and the Jamaica Conservation \& Development Trust (managers of the Blue and John Crow Mountains National Park). This work was supported by the U.S. Student Fulbright grant, and by awards from the Mohamed Bin Zayed Species Conservation Fund, the MacArthur Foundation, the Fort Worth Zoo and the Zoo Miami. Fieldwork was conducted under National Environment and Planning Agency (NEPA) Scientific Research permit 18/27.

\section{SUPPORTING INFORMATION}

Additional Supporting Information may be found in the online version of this article:

FIGURE S1. Variables identified by ten runs of the Random Forest variable selection algorithm.
TABLE S1. Collection locations with important climatic variables derived from Bioclim data set, habitat type, sampling dates, and the proportion of sampled frogs that tested positive for Batrachochytrium dendrobatidis.

TABLE S2. Bioclim variables used in modeling.

TABLE S3. Batrachochytrium dendrobatidis occurrence on frogs in Jamaica.

\section{LITERATURE CITED}

Alemu, J., M. Cazabon, L. Dempewolf, A. Hailey, R. Lehtinen, R. Mannette, K. Naranjit, and A. Roach. 2008. Presence of the chytrid fungus Batrachocbytrium dendrobatidis in populations of the critically endangered frog Mannophryne olmonae in Tobago, West Indies. EcoHealth 5: 34-39

Bancroft, B., B. Han, C. Searle, L. Biga, D. Olson, L. Kats, J. Lawler, and A. R. Blaustein. 2011. Species-level correlates of susceptibility to the pathogenic amphibian fungus Batrachochytrium dendrobatidis in the United States. Biodivers. Conserv. 20: 1911-1920.

Berger, L., A. Hyatt, R. Speare, and J. E. Longcore. 2005. Life cycle stages of the amphibian chytrid Batrachochytrium dendrobatidis. Dis Aquat Organ 68: 51-63.

Bisrat, S., M. White, K. Beard, and D. Cutler. 2012. Predicting the distribution potential of an invasive frog using remotely sensed data in Hawaii. Divers. Distrib. 18: 648-660.

Bivand, R., E. Pebesma, and V. Gomez-Rubio, 2008. Applied spatial data analysis with R. Springer, New York. Available at: http://www.asdar-book.org/.

Blaustein, A. R., S. S. Gervasi, P. T. Johnson, J. T. Hoverman, L. K. Belden, P. W. Bradley, and G. Y. XIE. 2012. Ecophysiology meets conservation: Understanding the role of disease in amphibian population declines. Proc. Biol. Sci. 367: 1688-1707.

Breiman, L. 2001. Random forests. Mach. Learn. 45: 5-32.

Briggs, C. J., R. A. Knapp, and V. Vredenburg. 2010. Enzootic and epizootic dynamics of the chytrid fungal pathogen of amphibians. Proc. Natl. Acad. Sci. U S A 107: 9695-9700.

Burrowes, P. A., R. L. Joglar, and D. Green. 2004. Potential causes for amphibian declines in Puerto Rico. Herpetologica 60: 141-154.

Chatfield, M. W., and C. Richards-Zawacki. 2011. Elevated temperature as a treatment for Batrachochytrium dendrobatidis infection in captive frogs. Dis. Aquat. Org. 94: 235-238.

Cleveland, W., E. Grosse, And W. Shyu. 1992. Local regression models. In J. M. Chambers and T. Hastie (Eds.). Statistical Models in S, pp. 309-376. Chapman Hall, New York.

Daskin, J., R. Alford, and R. Puschendorf. 2011. Short-term exposure to warm microhabitats could explain amphibian persistence with Batrachochytrium dendrobatidis. PLoS ONE 6: 1-4.

Diaz, L., A. Cadiz, A. Chong, And A. Silva. 2007. First report of chytridiomycosis in a dying toad (Anura : Bufonidae) from Cuba: A new conservation challenge for the island. EcoHealth 4: 172-175.

Diesel, R., G. Baurle, And P. Vogel. 1995. Cave breeding and froglet transport-A novel pattern of anuran brood care in the Jamaican frog, Eleutherodactylus cundalli. Copeia 1995: 354-360.

Drew, A., E. Allen, And L. Allen. 2006. Analysis of climatic and geographic factors affecting the presence of chytridiomycosis in Australia. Dis. Aquat. Org. 68: 245-250.

Flechas, S. V., C. Sarmiento, And A. Amezquita. 2012. Bd on the beach: High prevalence of Batrachochytrium dendrobatidis in the lowland forests of Gorgona Island (Colombia, South America). EcoHealth 9: 298302.

Forrest, M.J., AND M.A. SChLAepfer. 2011. Nothing a hot bath won't cure: Infection rates of amphibian chytrid fungus correlate negatively with water temperature under natural field settings. PLoS ONE 6: $1-9$. 
Geiger, C., E. Kupfer, S. Schar, S. Wolf, and B. R. Schmidt. 2011. Elevated temperature clears chytrid fungus infections from tadpoles of the midwife toad, Alytes obstetricans. Amphibia-Reptilia 32: 276-280.

Ghirardi, R., M. PerotTi, M. Steciow, M. Arellano, and G. Natale. 2011. Potential distribution of Batrachochytrium dendrobatidis in Argentina: Implications in amphibian conservation. Hydrobiologia 659: 111-115.

Gomez-Mestre, I., R. A. Pyron, And J. J. Wiens. 2012. Phylogenetic analyses reveal unexpected patterns in the evolution of reproductive modes in frogs. Evolution 66: 3687-3700.

Gray, M. J., D. L. Miller, and J. T. Hoverman. 2009. Ecology and pathology of amphibian ranaviruses. Dis. Aquat. Org. 87: 243-266.

Green, P., and B. Silverman, 1994. Nonparametric regression and generalized linear models: A roughness penalty approach. Chapman and Hall, New York.

Hastie, T., And R. Tibshirani. 1990. Generalized additive models. Chapman and Hall, New York.

Hauselberger, K., And R. Alford. 2012. Prevalence of Batrachochytrium dendrobatidis infection is extremely low in direct-developing Australian microhylids. Dis. Aquat. Org. 100: 191-200.

Hedges, S. 1989. An island radiation allozyme evolution in Jamaican frogs of the genus Eleutherodactylus (Leptodactylidae). Carib. J. Sci. 25: 123-147.

Hedges, S.B., 2011. An overview of the evolution and conservation of West Indian amphibians and reptiles. In A. Hailey, B. Wilson, and J. Horrocks (Eds.). Conservation of Caribbean Island Herpetofaunas, Vol 1: Conservation biology and the wider Caribbean. pp. 19-30. EJ Brill, Leiden, Netherlands.

Hijmans, R., S. Cameron, J. Parra, P. Jones, and A. Jarvis. 2005. Very high resolution interpolated climate surfaces for global land areas. Int. J. Climatol. 25: 1965-1978.

Holmes, I., K. McLaren, and B. Wilson. 2012. Surveys for frog diversity and Batrachochytrium dendrobatidis in Jamaica. Herpetol. Rev. 43: 278 282.

Hossack, B. R., W. H. Lowe, J. Ware, and P. S. Corn. 2013. Disease in a dynamic landscape: Host behavior and wildfire reduce amphibian chytrid infection. Biol. Conserv. 157: 293-299.

Hyatt, A., R. Speare, A. Cunningham, and C. Carey. 2010. Amphibian chytridiomycosis. Dis. Aquat. Org. 92: 89-91.

Lanoo, M.J., D. Townsend, and R. Wassersug. 1987. Larval life in the leaves: Arboreal tadpole types with special attention to the morphology, ecology and behavior of the oophagous Osteopilus brunneus (Hylidae) larva. Fieldiana Zool. new series no. 38: 1-32.

Liaw, A., AND M. Wiener. 2002. Classification and regression by randomForest. R News 2: 18-22.

Lips, K., F. Brem, R. Brenes, J. Reeve, R. Alford, J. Voyles, C. Carey, L. J. Livo, A. Pessier, And J. Collins. 2006. Emerging infectious disease and the loss of biodiversity in a Neotropical amphibian community. Proc. Natl. Acad. Sci. U S A 103: 3165-3170.

Longcore, J. E., A. P. Pessier, And D. Nichols. 1999. Batrachochytrium dendrobatidis gen et sp nov, a chytrid pathogenic to amphibians. Mycologia 91: 219-227.

Longo, A. V., And P. A. Burrowes. 2010. Persistence with chytridiomycosis does not assure survival of direct-developing frogs. EcoHealth 7: 185-195.

Longo, A. V., R. Ossiboff, K. R. Zamudio, and P. A. Burrowes. 2013. Lability in host defenses: Terrestrial frogs die from chytridiomycosis under enzootic conditions. J. Wildl. Dis. 49: 197-199.

Martel, A., A. Spitzen-van der Sluijs, M. Blooi, W. Bert, R. Ducatelle, M.C. Fisher, A. Woeltjes, W. Bosman, K. Chiers, F. Bossuyt, and F. PAsmans. 2013. Batrachochytrium salamandrivorans sp. nov. causes lethal chytridiomycosis in amphibians. Proc. Natl. Acad. Sci. U S A, 110: 15325-15329.

Meyer, P.E., 2008. Information-Theoretic Variable Selection and Network Inference from Microarray Data. PhD Dissertation. l'Université Libre de Bruxelles, Brussels, Belgium.

Meyer, P.E., 2009. infotheo: Information-theoretic measures, Available at: http://CRAN.R-project.org/package=infotheo.
Moen, D., And J. Weins. 2009. Phylogenetic evidence for competitively driven divergence: Body-size evolution in Caribbean treefrogs (Hylidae: Osteopilus). Evolution 63: 195-214.

Moran, P. 1950. Notes on continuous stochastic phenomena. Biometrika 37: 17-23.

Moss, A. S., N. S. Reddy, I. M. DortaJ, and M. J. S. Francisco. 2008. Chemotaxis of the amphibian pathogen Batrachochytrium dendrobatidis and its response to a variety of attractants. Mycologia 100: 1-5.

Murray, K. A., R. W. Retallick, R. Puschendorf, L. F. Skeratt, D. Rosauer, H. I. McCallum, L. Berger, R. Speare, and J. VanDerWal. 2011. Assessing spatial patterns of disease risk to biodiversity: Implications for the management of the amphibian pathogen, Batrachochytrium dendrobatidis. J. Appl. Ecol. 48: 163-173.

Murray, K.A., L.F. Skeratt, S. Garland, D. Kriticos, and H.I. McCallum. 2013. Whether the weather drives patterns of endemic amphibian chytridiomycosis: A pathogen proliferation approach. PLoS ONE 8: $1-11$.

Murray, K. A., L. F. Skeratt, R. Speare, and H. I. McCallum. 2009. Impact and dynamics of disease in species threatened by the amphibian chytrid fungus, Batrachochytrium dendrobatidis. Conserv. Biol. 23: 1242-1252.

Ocock, J., J. J. Rowley, T. Penman, T. Rayner, and R. Kingsford. 2013. Amphibian chytrid prevalence in an amphibian community in arid Australia. EcoHealth 10: 77-81.

Olson, D., D. Aanensen, K. Ronnenberg, C. Powell, S. Walker, J. Bielby, T. Garner, G. Weaver, And M.C. Fisher. 2013. Mapping the global emergence of Batrachochytrium dendrobatidis, the amphibian chytrid fungus. PLoS ONE 8: 1-13.

Oppel, S., A. Meirinho, I. Ramirez, B. Gardner, A. O’Connell, P. Miller, AND M. Louzao. 2012. Comparison of five modelling techniques to predict the spatial distribution and abundance of seabirds. Biol. Conserv. 156: 94-104.

Paradis, E., J. Claude, and K. Strimmer. 2004. APE: Analyses of phylogenetics and evolution in R language. Bioinformatics 20: 289-290.

Patel, Y., J. Cavin, And M. Moore. 2012. Morphological anomalies as indicators of chytrid infection in Bufo marinus from Trinidad, West Indies. Bios 83: 75-80.

Pebesma, E., and R. Bivand, 2005. Classes and methods for spatial data in R. R News 5: 9-13.

Phillips, S., R. Anderson, And R. Schapire. 2006. Maximum entropy modeling of species geographic distributions. Ecol. Model. 190: 231-259.

Phillips, S., AND M. Dudik. 2008. Modelling of species distributions with MaxEnt: New extensions and a comprehensive evaluation. Ecography 31: 161-175.

Piotrowski, J. S., S. L. Annis, and J. E. Longcore. 2004. Physiology of Batrachochytrium dendrobatidis, a chytrid pathogen of amphibians. Mycologia 96: 9-15.

Puschendorf, R., A. C. Carnaval, J. VanderWal, H. Zumbado-Ulate, G. Chaves, F. Bolanos, And R. A. Alford. 2009. Distribution models for the amphibian chytrid Batrachochytrium dendrobatidis in Costa Rica: Proposing climatic refuges as a conservation tool. Divers. Distrib. 15: 401-408.

Puschendorf, R., C. J. Hoskin, S. D. Cashins, K. McDonald, L. F. Skeratt, J. VanderWal, and R. A. Alford. 2011. Environmental refuge from disease- driven amphibian extinction. Conserv. Biol. 25: 956-964.

R Development Core Team, 2010. R: A language and environment for statistical computing. R Foundation for Statistical Computing, Vienna, Austria. Available at: http://www.R-project.org/.

Ron, S. 2005. Predicting the distribution of the amphibian pathogen Batrachochytrium dendrobatidis in the New World. Biotropica 37: 209-221.

Rosenblum, E.B., T.Y. James, K.R. Zamudio, T.J. Pooren, D. Ilut, D. Rodriguez, J.M. Eastman, K. Richards-Hrdlicka, S. Joneson, T. S. Jenkinson, J.E. Longcore, G. Parra Olea, L. F. Toledo, M. L. Arellano, E. M. Medina, S. Restrepo, S. V. Flechas, L. Berger, C. J. Briggs, AND J. E. Stajich. 2013. Complex history of the amphibian-killing chytrid fungus revealed with genome data resequencing. Proc. Natl Acad. Sci. U S A, 110: 9385-9390. 
Rowley, J. J., And R. A. Alford. 2007. Behaviour of Australian rainforest stream frogs may affect the transmission of chytridiomycosis. Dis Aquat Organ 77: 1-9.

Rowley, J.J., And R.A. Alford. 2013. Hot bodies protect amphibians against chytrid infection in nature. Scientific Reports 3: 1-4.

Sehgal, R., W. Buermann, R. Harrigan, C. Bonneaud, C. Loiseau, A. Chasar, I. Sepil, G. Valkiunas, T. Iezhova, S. SaAtchi, and T. SMITH. 2011. Spatially explicit predictions of blood parasites in a widely distributed African rainforest bird. Proc Biol Sci 278: 10251033.

Stevenson, L., R. Alford, S. Bell, E. Roznik, L. Berger, and D. Pike. 2013. Variation in thermal performance of a widespread pathogen, the amphibian chytrid fungus Batrachochytrium dendrobatidis. PLoS ONE 8: e73830.

Van Rooij, P., A. Martel, K. D’Herde, M. Brutyn, S. Croubels, R. Ducatelle, F. Haesebrouck, and F. Pasmans. 2012. Germ tube mediated invasion of Batrachochytrium dendrobatidis in amphibian skin is host dependent. PLoS ONE 7: 1-8.

Voyles, J., L. R. Johnson, C. J. Briggs, S. D. Cashins, R. A. Alford, L. F. Lee Berger, R. Speare Skeratt, and E. B. Rosenblum. 2012. Temperature alters reproductive life history patterns in Batrachochytrium dendrobatidis, a lethal pathogen associated with the global loss of amphibians. Ecol Evol 2: 2241-2249.

Walke, J., R. Harris, L. K. Reinert, L. A. Rollins-Smith, and D. C. Wood HAMs. 2011. Social immunity in amphibians: Evidence for vertical transmission of innate defenses. Biotropica 43: 296-400.

Whitfield, S. M., J. Kerby, L. R. Gentry, and M. A. Donnelly. 2012. Temporal variation in infection prevalence by the amphibian chytrid fungus in three species of frogs at La Selva, Costa Rica. Biotropica 44: 779-784.

Zambrano-Bigiarini, M., 2011. hydroGOF: Goodness-of-fit functions for comparison of simulated and observed hydrological time series. Available at: http://CRAN.R-project.org/package=hydroGOF. 